Research Article

\title{
Fault Diagnosis Research on Impact System of Hydraulic Rock Drill Based on Internal Mechanism Testing Method
}

\author{
Yelin Li (D), Youxin Luo, and Xiao Wu \\ Hunan Province Cooperative Innovation Center for the Construction \& Development of Dongting Lake Ecological Economic \\ Zone, Hunan University of Arts and Science, Changde 415000, China
}

Correspondence should be addressed to Yelin Li; liyelin0403@aliyun.com

Received 26 February 2018; Revised 6 June 2018; Accepted 20 June 2018; Published 18 July 2018

Academic Editor: Cristina Castejón

Copyright $(92018$ Yelin Li et al. This is an open access article distributed under the Creative Commons Attribution License, which permits unrestricted use, distribution, and reproduction in any medium, provided the original work is properly cited.

In the production and manufacturing process of hydraulic rock drill, there are small impact energy and low impact frequency, and a fault diagnosis method based on the internal mechanism testing and testing of the hydraulic rock drill is proposed. This method is used to test the change law of hydraulic oil in the rock drill, by retaining the test holes on the cylinder body and other important components of the hydraulic rock drill. At the same time, the mathematical method is used to deal with the test curve, and the influence of pressure pulsation characteristics of the front and rear chambers of the impact piston and the left and right valve chambers of the reversing valve on the impact performance of the rock drill is analyzed. Based on Newton's law, the model of the impact piston and reversing valve is established. According to the velocity and other parameters of the impact piston, the size of the impact piston switch point is calculated. The coupling between the movement of the impact piston and the movement of the reversing valve is analyzed according to the model established. Comparing the results of the experimental data, the correctness of the fault diagnosis analysis method and model is verified. The effect of the fault rock drill and the improved model is compared, and the theoretical basis is provided for the fault diagnosis of the rock drill and the design of a new type of rock drill.

\section{Introduction}

At present, hydraulic rock drill is widely used in mining, tunneling, and building industries. It is the core component of hydraulic drill. Its inner channel is complicated and interlaced, which brings great difficulty to the performance testing of the rock drill in the production and manufacturing process [1].

The main testing methods of the rock drill are stress wave method, photoelectric displacement method, and highspeed photography method. The stress wave method is used to test the transmission effect of stress wave in the drill rod, and the impact energy of the hydraulic rock drill can be calculated by the stress wave test. The photoelectric displacement method is used to paste the black and white light rod in the tail of the piston, as far as possible without changing the piston mass. The photoelectric displacement sensor is used to detect the black and white marks on the light rod. The movement law of the piston is obtained by changing the differential method, and the high-speed photography method uses the high-speed camera to shoot the tail of the piston directly and to analyze the movement law of the piston by the slow replay. The aforementioned methods focus on testing and researching the impact of piston movement and energy generation but ignore the test and analysis of the internal mechanism [2-5].

Taking the hydraulic drill with no constant-pressurized chamber as an example, through the test and analysis of the coupling between the internal impact piston and the reversing valve of the rock drill, a testing method which can be applied to the manufacturing process of the rock drill can be studied, which can provide a theoretical basis for the fault diagnosis of the rock drill and the design of a new type of rock drill.

\section{Impact Principle of Hydraulic Rock Drill}

The drilling principle of the hydraulic rock drill is shown in Figure 1. The impact piston, the damping piston, and the shank are inside the hydraulic rock drill. The shank is 


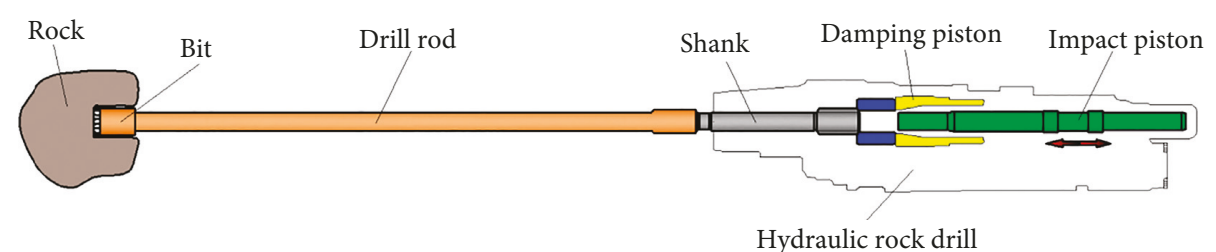

FIgURE 1: Drilling system principle.

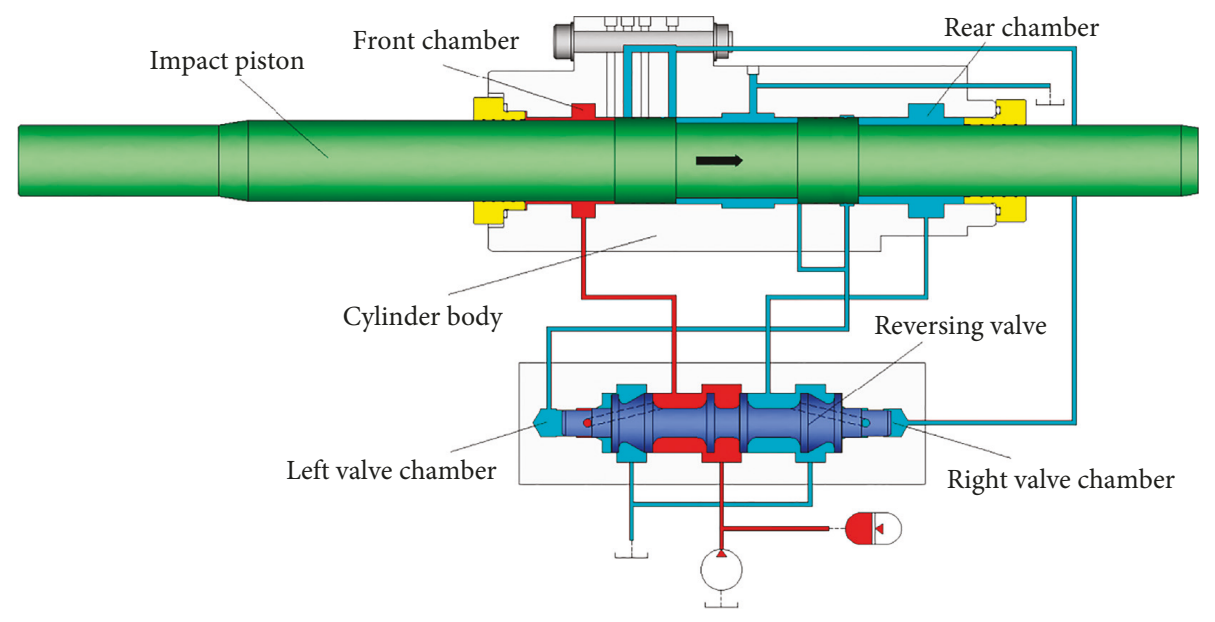

FIGURE 2: Impact and reversing mechanism principle.

connected with the drill rod through the thread, and the bit is connected to the other end of the drill rod through the thread. In the drilling process of the rock drill, the impact piston impacts the shank to break the rock. The impact piston strikes the shank to produce the stress wave, and the stress wave is transmitted to the rock through multiple transmission, and then, the rock is broken. The reflected wave is absorbed and utilized by the damping piston [6].

The impact mechanism of the hydraulic rock drill is mainly composed of cylinder body, impact piston, reversing valve, and high pressure accumulator [7]. The impact piston and the reversing valve are connected through the inner channel in the cylinder, moving under the action of hydraulic oil. The coupling between the impact piston and the reversing valve is the key factor of the working performance of the hydraulic rock drill. The structure principle is shown in Figure 2.

The impact piston movement of the hydraulic rock drill is divided into three processes: return, stroke, and impact, and the reversing valve makes a switch of direction in time with the impact piston in the three movement processes [8]. But there are many key points in the three processes. The whole cycle can be divided into more than 30 movement states. In order to increase the operability of the research, the movement state is simplified into 8 states:

State 1: The impact piston returns acceleration; the reversing valve is stationary. The cylinder body front chamber is at high pressure, and the rear chamber and left-right valve chambers are at low pressure.

State 2: The impact piston returns acceleration; the reversing valve starts reversing. The cylinder body front chamber and right valve chambers are at high pressure, and the rear chamber and left valve chamber are at low pressure.

State 3: The impact piston return trip starts; the reversing valve continues to reverse. The cylinder body front-rear chambers and left-right valve chambers are at the pressure switch point.

State 4: The reversing valve completes reversing; the impact piston slows down to stop. The cylinder body rear chamber is at high pressure, and the front chamber and left-right valve chambers are at low pressure.

State 5: The impact piston strokes; the reversing valve is stationary. The cylinder body rear chamber is at high pressure, and the front chamber and left-right valve chambers are at low pressure.

State 6: The impact piston strokes; the reversing valve starts reversing. The cylinder body rear chamber and left valve chamber are at high pressure, and the front chamber and right valve chamber are at low pressure.

State 7: The impact piston impacts the shank; the reversing valve continues to reverse. The cylinder body front-rear chambers and left-right valve chambers are at the pressure switch point.

State 8: The impact piston returns acceleration; the reversing valve stops. This state is the same as state 1 and enters the second movement cycle.

\section{Mechanism Test Design}

3.1. Test System Design. The experimental platform is designed to test the rock drill, and the pumping station 


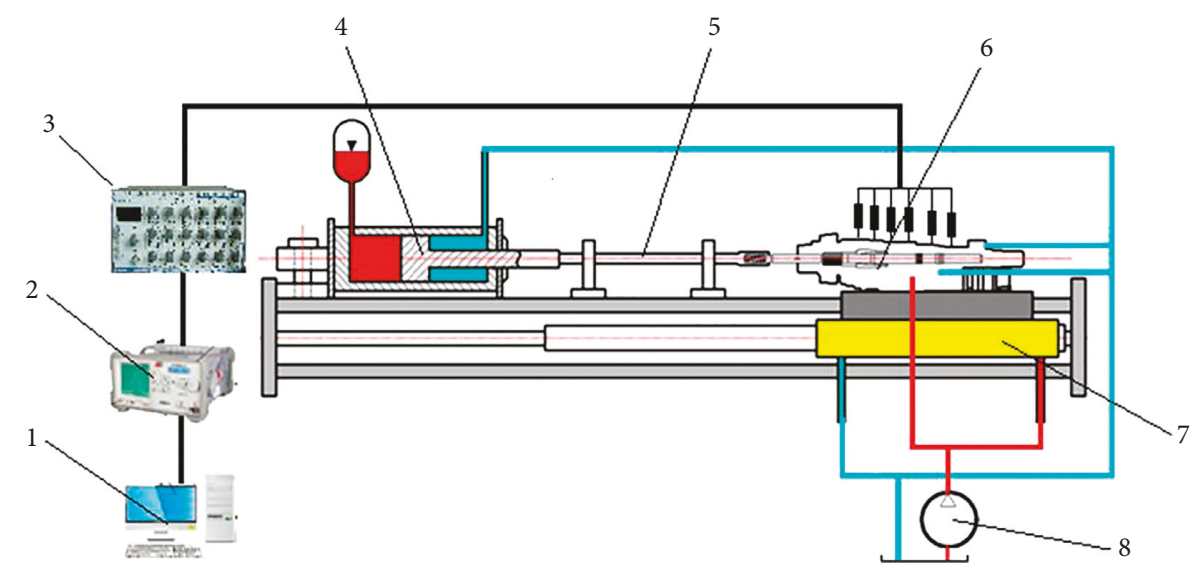

FIGURE 3: Impact and reversing mechanism principle. 1: computer; 2: data acquisition system; 3: signal amplifier; 4: punching cylinder; 5: drill rod; 6: hydraulic rock drill; 7: propulsion cylinder; 8: hydraulic pumping station.

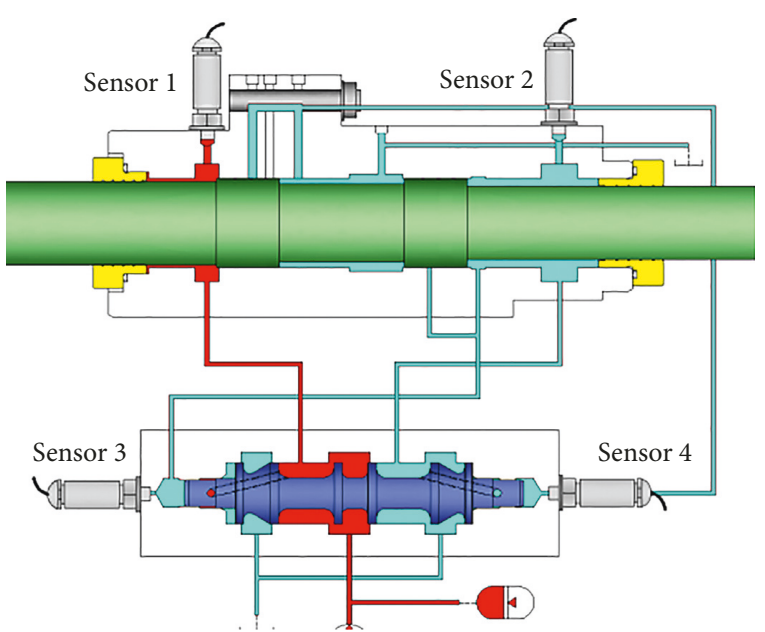

(a)

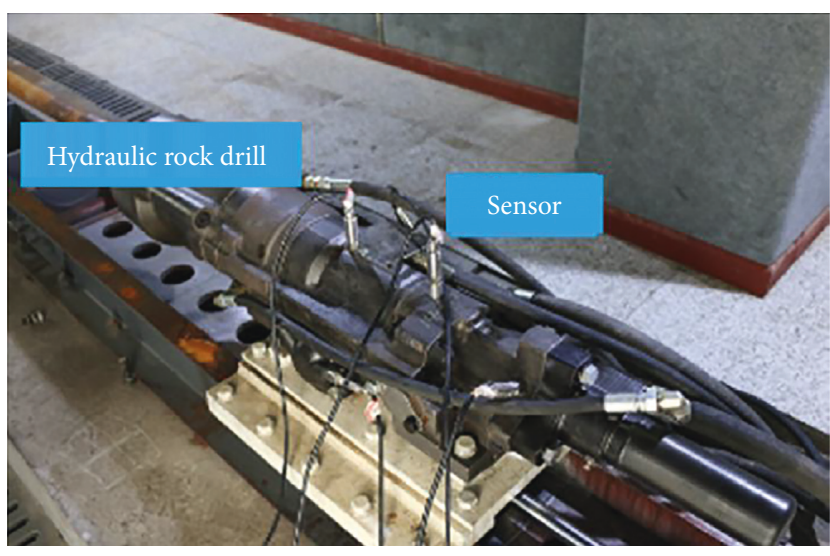

(b)

FIGURE 4: Sensor installation location in impact and reversing mechanism.

supplies fuel to the propulsion cylinder, the punching cylinder, and the hydraulic rock drill. The rock drill is installed on the experimental bench, which is moved by the propulsion cylinder to propel the rock drill. The rock drill is tightly pressed by the drill rod, and the punching cylinder can adjust the pressure to simulate the rock with different hardness. Some sensors are connected to the rock drill. The voltage signal is amplified by a signal amplifier. These sensors are collected and transmitted to the computer by the data acquisition system [9]. The test system is shown in Figure 3.

3.2. Test Point of Sensor Design. According to the principle and state analysis of the hydraulic rock drill, it can be seen that the pressures in the front-rear chambers and the leftright valve chambers are the key to the impact process of the rock drill. This test will focus on the front-rear chambers and the left-right valve chambers of the rock drill so as to obtain the performance of new rock drill [10-12].

Design the pressure test point of the front-rear chambers; the hole diameter is not too large to increase the volume of the front and rear chambers of the cylinder body. The throughhole connection of $\Phi=2 \mathrm{~mm}$ can be selected, and the threaded holes installed by the sensor are reserved on the surface. Design the pressure test point of the reversing valve, drill the threaded hole in the center of the left and right valve cover, and install the sensor directly on the cover of the reversing valve. The overall installations are shown in Figure 4.

\section{Experimental Analysis}

4.1. Parameter Setting. The experimental equipment is connected, and the hydraulic pump station is set up to set the propulsion pressure, inflow pressure of impact, no-load damping pressure, and other experimental parameters, as shown in Table 1.

4.2. Data Analysis. In the experiment, four groups of data were tested, namely, the front-rear chambers of the piston and the left-right valve chambers of the reversing valve $[13,14]$. The four sets of data were collected at the same time, as shown in Figure 5. 
TABle 1: Test initial data setting.

\begin{tabular}{lccc}
\hline Number & Parameter & Setting valve (MPa) & Display mode \\
\hline 1 & Inflow pressure of impact & 20 & Sensor \\
2 & No-load damping pressure & 3.5 & Sensor \\
3 & Load damping pressure & 8 & Sensor \\
4 & Propulsion pressure & 6 & Sensor \\
5 & Initial nitrogen charging pressure & 3.5 & Gauge pressure \\
6 & of damping accumulator & & Gauge pressure \\
& Initial nitrogen charging pressure of & 11.5 & high pressure accumulator \\
\hline
\end{tabular}

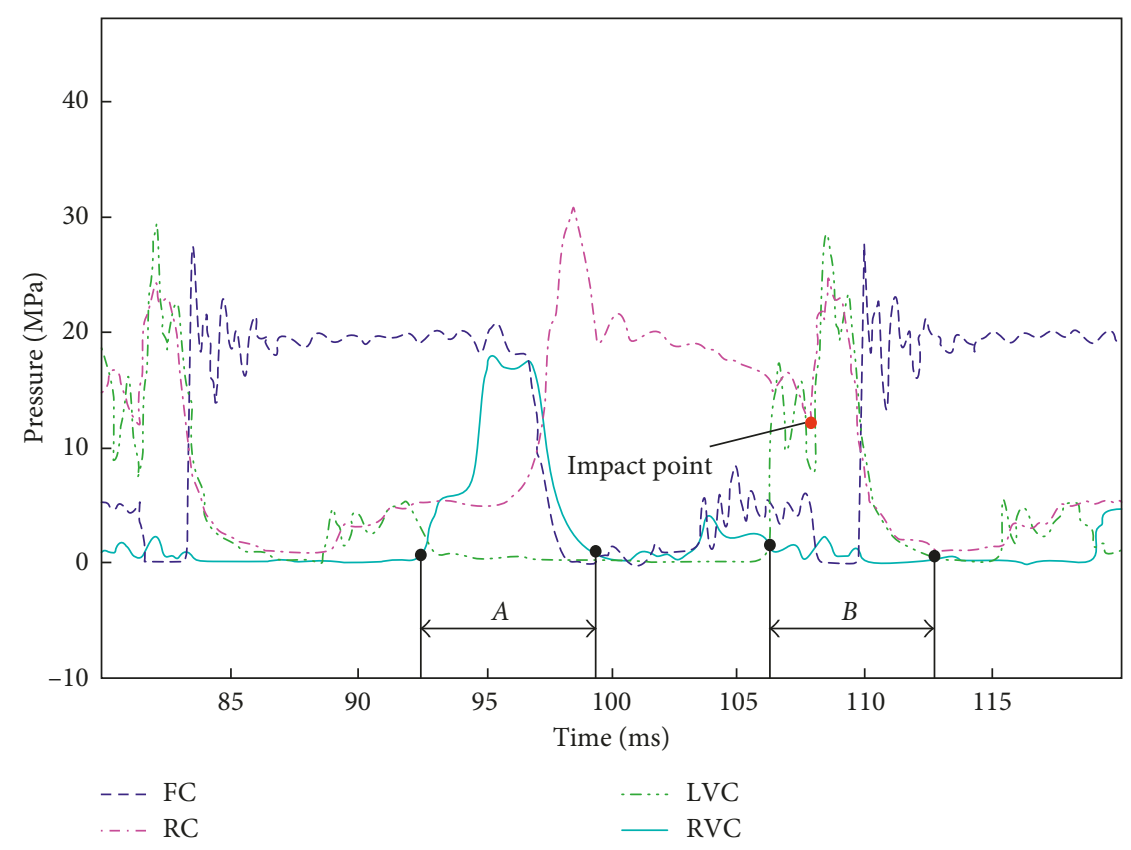

FIGURE 5: Pressure curves of testing mechanism. FC: front chamber; RC: rear chamber; LVC: left valve chamber; RVC: right valve chamber.

The characteristics of test curves are mainly analyzed from the following aspects.

4.2.1. Impact Point. In the movement state analyzed earlier, the impact piston impacts the shank in state 7 , and the impact time should be reflected in the curve. Before the impact, the rear chamber should be at high pressure to push the piston forward, the pressure of the rear chamber descends suddenly to $13 \mathrm{MPa}$ at $108 \mathrm{~ms}$, and then the pressure rises to $30 \mathrm{MPa}$. This phenomenon indicates that the impact piston impacts the shank forward (the pressure decreases) and produces the rebound (the pressure rises), and the position of the impact point is judged as shown in Figure 5.

4.2.2. The Change Law of Pressure in Front-Rear Chambers. After the impact point, the pressure of the chamber continues to rise, and the impact piston has the rebound velocity after the impact is completed. To push the piston to carry out the return movement, the best conditions are reducing the rear chamber pressure to $0 \mathrm{MPa}$ and increasing the front chamber pressure rapidly.
4.2.3. The Change Law of Pressure in Left-Right Valve Chambers. The reversing valve should be switched and the left valve chamber pressure will drop rapidly after the impact piston is struck. But in the test curve, the continuous interval $A$ of the right valve chamber pressure and the continuous interval $B$ of the left valve chamber pressure of the reversing valve are too long, which means that the switch is not sensitive enough, resulting in the impact frequency of about $36 \mathrm{~Hz}$, which is far from the $50 \mathrm{~Hz}$ standard of the design.

4.2.4. Abnormal Performance. The analysis of the test curves shows that the impact frequency of the new type of rock drill is low and the impact piston velocity is small. It is necessary to further improve the internal structure design and adjust the rock drill to the best state.

\section{Fault Diagnosis Analysis}

5.1. Data Processing. Taking the impact point as the benchmark, the movement law of the impact piston is obtained by curve integral processing. Formula (1) can be obtained by momentum conservation: 


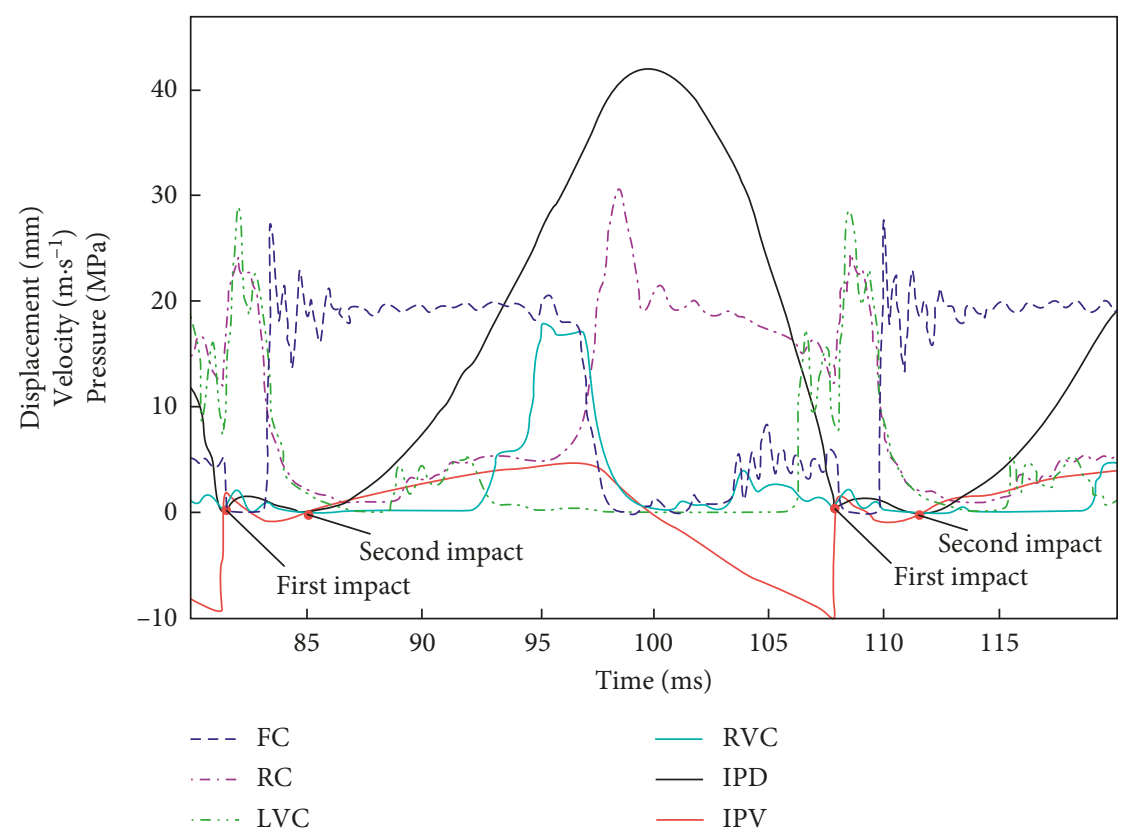

FIGURE 6: Pressure curves of chamber and integral curves of piston velocity and displacement. FC: front chamber; RC: rear chamber; LVC: left valve chamber; RVC: right valve chamber; IPD: impact piston displacement; IPV: impact piston velocity.

$$
F t=m v,
$$

where $F$ is the impact force of the impact piston in the stroke process $(\mathrm{N}), t$ is the action time between force $F$ and impact piston (ms), $m$ is the impact piston mass $(\mathrm{kg})$, and $v$ is the impact piston velocity $(\mathrm{m} / \mathrm{s})$.

Among them,

$$
F=P_{1} A_{1}-P_{2} A_{2}
$$

where $P_{1}$ is the front chamber pressure $(\mathrm{MPa}), P_{2}$ is the rear chamber pressure $(\mathrm{MPa}), A_{1}$ is the effective working area of the front chamber $\left(\mathrm{mm}^{2}\right)$, and $A_{2}$ is the effective working area of the rear chamber $\left(\mathrm{mm}^{2}\right)$.

The force $F$ of the impact piston is integrated:

$$
\int_{a i}^{b i} F d t=m v
$$

Formula (2) is substituted into (3):

$$
\int_{a i}^{b i}\left(P_{1} A_{1}-P_{2} A_{2}\right) d t=m v .
$$

The velocity of each moment $v_{i}$ is solved by the following equation:

$$
v_{i}=\frac{A_{1} \int_{a i}^{b i} P_{1} d t-A_{2} \int_{a i}^{b i} P_{2} d t}{m} .
$$

The displacement curve is obtained after integrating the velocity curve, as shown in Figure 6.

It is clearly seen from Figure 6 that the two changes of the displacement and velocity curve in one period are 0 , indicating a period of second impacts between the impact piston and the shank. At this time, the impact piston and the reversing valve are not coupled properly, and the energy is not applied efficiently to the drilling process, and the energy loss is in the second internal impacts. The second impact caused the impact piston to have insufficient rebound speed, the return distance is small, the stroke energy cannot be fully utilized, and finally, the impact energy and impact frequency cannot reach the expected target. The main reason for the second impacts is that the reversing valve is not sensitive enough.

5.2. Coupling Modeling. The coupling relationship between the impact piston and the reversing valve is analyzed. In state 7 , the impact piston impacts the shank moment, the reversing valve should be in the position shown in Figure 7 , and the connection of each valve port and the pipe in the reversing valve is in a critical closing state [15-17].

5.2.1. Coupling Equation. The best coupling relationship between the impact piston and the reversing valve is obtained when the direction is changed from state 6 to state 7 , the stroke of the impact piston reaches the impact point, and the stroke of the reversing valve reaches the critical state of the reversing valve, for which the time used is the same, and the following equation is established:

$$
\frac{s_{\mathrm{p} 6}}{\dot{x}_{\mathrm{p}}}=\frac{s_{\mathrm{v} 6}}{\dot{x}_{\mathrm{v}}}
$$

where $x_{\mathrm{p}}$ is the impact piston displacement $(\mathrm{mm}), s_{\mathrm{p} 6}$ is the distance of the impact piston from state 6 to state $7(\mathrm{~mm}), x_{\mathrm{v}}$ is the reversing valve displacement $(\mathrm{mm})$, and $s_{\mathrm{v} 6}$ is the distance of reversing valve from state 6 to state $7(\mathrm{~mm})$.

\subsubsection{Impact Piston Movement Differential Equation.} The impact mechanism model is as shown in Figure 8. The key parts of the coupling between the impact piston and the 


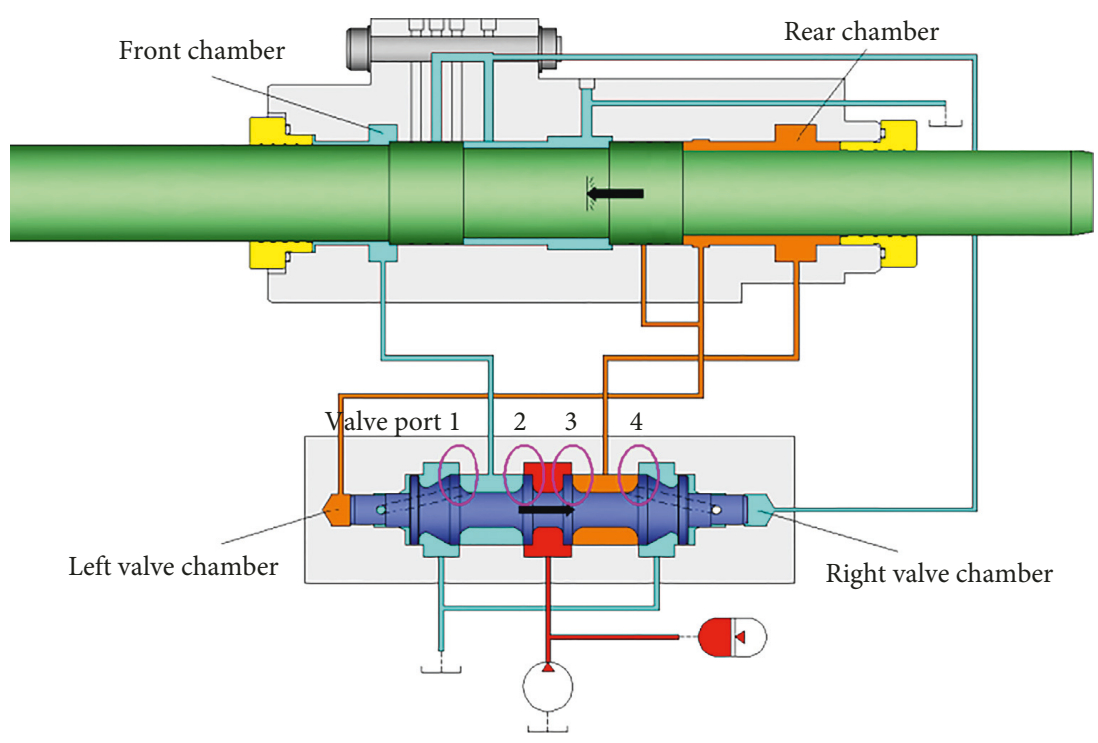

FIGURE 7: Impact piston and valve position in state 7.

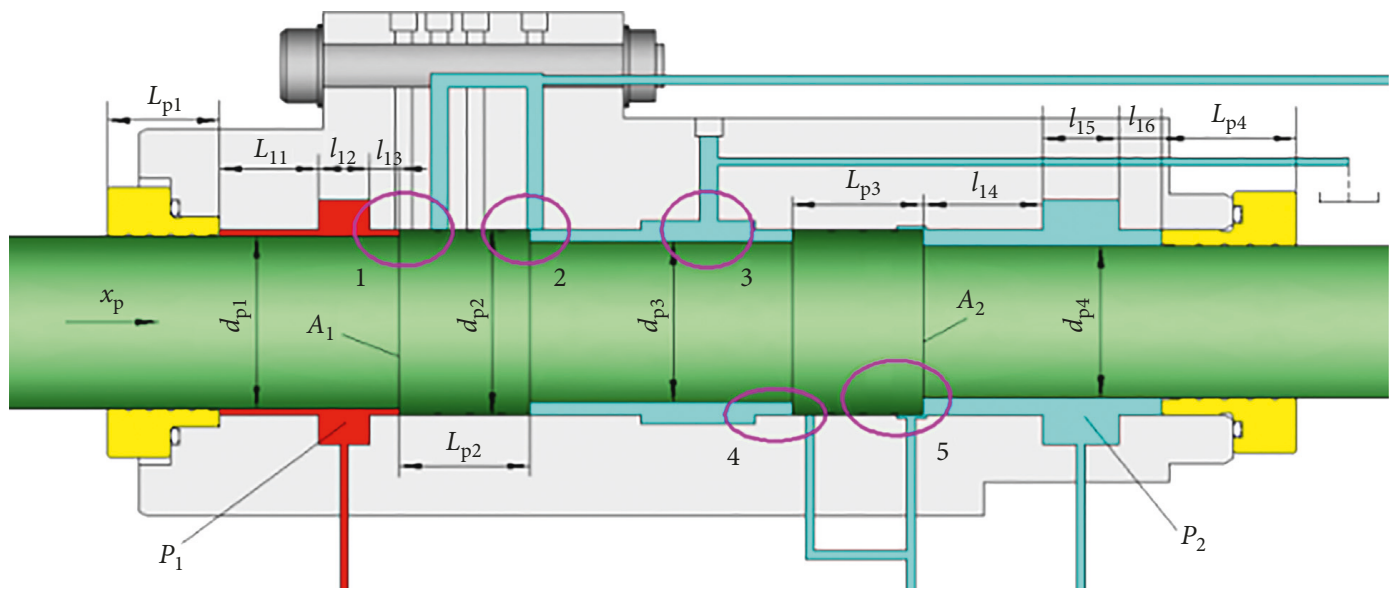

FIGURE 8: Impact mechanism.

reversing valve are the circled parts $1,2,3,4$, and 5, and the following differential equation is established:

$$
m_{\mathrm{p}} \ddot{x}_{\mathrm{p}}+K_{\mathrm{p}} \dot{x}_{\mathrm{p}}+F_{1} \frac{\left|\dot{x}_{\mathrm{p}}\right|}{\dot{x}_{\mathrm{p}}}=A_{1} P_{1}+A_{2} P_{2},
$$

where $m_{\mathrm{p}}$ is the mass of the impact piston $(\mathrm{kg}), K_{\mathrm{p}}$ is the coefficient of viscous resistance, and $F_{1}$ is the friction force of seal (N).

\subsubsection{Reversing Valve Movement Differential Equation.} The reversing valve model is as shown in Figure 9. The key parts of the coupling between the impact piston and the reversing valve are the circled parts $1,2,3,4,5,6$, and 7 , and the following differential equation is established:

$$
\begin{aligned}
m_{\mathrm{v}} \ddot{x}_{\mathrm{v}}+K_{\mathrm{v}} \dot{x}_{\mathrm{v}}= & A_{\mathrm{v} 1} P_{4}+A_{\mathrm{v} 2} P_{6}+A_{\mathrm{v} 3} P_{8} \\
& -A_{\mathrm{v} 1} P_{3}-A_{\mathrm{v} 2} P_{5}-A_{\mathrm{v} 3} P_{7},
\end{aligned}
$$

where $m_{\mathrm{v}}$ is the mass of the reversing valve $(\mathrm{kg}), x_{\mathrm{v}}$ is the displacement of the reversing valve $(\mathrm{mm}), K_{\mathrm{v}}$ is the coefficient of viscous resistance, $P_{3}$ is the pressure of the left valve chamber $(\mathrm{MPa}), P_{4}$ is the pressure of the right valve chamber (MPa), $P_{5}$ is the initial return pressure in the left side ( $\left.\mathrm{MPa}\right)$, $P_{6}$ is the initial return pressure in the right side $(\mathrm{MPa}), P_{7}$ is the damping pressure in the left side $(\mathrm{MPa}), P_{8}$ is the damping pressure in the right side $(\mathrm{MPa})$, and $A_{\mathrm{v} 1}, A_{\mathrm{v} 2}$, and $A_{\mathrm{v} 3}$ are the compression areas of the reversing valve $\left(\mathrm{m}^{2}\right)$.

5.3. Fault Diagnosis. The internal parameters of the rock drill are incorporated into the model, and the coupling parameters $\Delta t_{1}$ and $\Delta t_{2}$ are obtained by the following equation:

$$
\begin{gathered}
\Delta t_{1}=\frac{s_{\mathrm{p} 6}}{\dot{x}_{\mathrm{p}}}=1.07 \mathrm{~ms}, \\
\Delta t_{2}=\frac{s_{\mathrm{v} 6}}{\dot{x}_{\mathrm{v}}}=1.93 \mathrm{~ms} .
\end{gathered}
$$




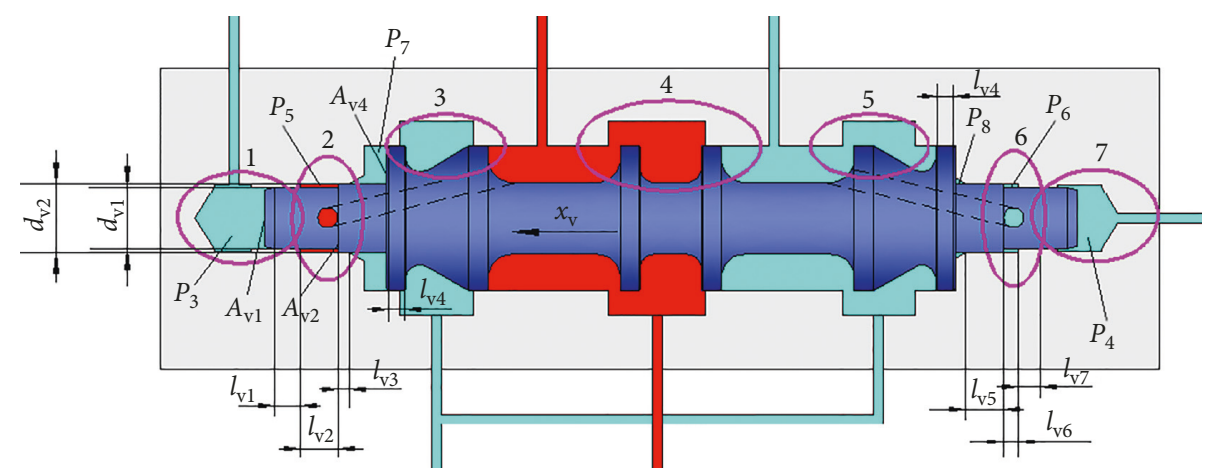

FIGURE 9: Reversing mechanism.

The reversing time is nearly twice as much as the impact time. At this time, the coupling between the impact piston and the reversing valve is extremely poor, and the structural design of the key position of the reversing valve is analyzed. Figure 10 shows the magnified image of the circled key part 3 shown in Figure 9.

The structure mainly controls the speed of the reversing valve, neither too fast nor too slow. If the reversing speed is too fast, the pressure oil of the front chamber is switched to high pressure when the impact piston does not impact the shank, which will reduce the impact velocity of the shock piston. The impact piston impacts the high pressure oil of the front chamber at the highest speed, not the shank. If the velocity of the reversing valve is too slow, the pressure of the rear chamber is still high, the high pressure will cause second impact after the impact piston rebound, and the return energy will be lost. This is the problem of the product.

The clearance flow equation of the structure is established by the following equation:

$$
\begin{aligned}
& Q_{\mathrm{v} 7}=C_{\mathrm{d}} \pi \varepsilon\left(2 R_{\mathrm{v} 3}-\varepsilon\right) \sqrt{\frac{2\left(P_{7}-P_{0}\right)}{\rho},} \\
& Q_{\mathrm{v} 7}=\pi\left(R_{\mathrm{v} 3}^{2}-R_{\mathrm{v} 2}^{2}\right) L_{\mathrm{v} 7} \Delta t,
\end{aligned}
$$

where the $C_{\mathrm{d}}$ is the flow coefficient, $\varepsilon$ is the gap between the cylinder and the reversing valve, which controls the valve velocity $(\mathrm{mm}), P_{0}$ is the return oil pressure (MPa), $R_{\mathrm{v} i}$ and $L_{\mathrm{v} i}$ are the radius and length $(\mathrm{mm})$ of each segment on the reversing valve, respectively, as shown in Figure 10, and $\Delta t$ is the time (ms) for all the oil discharge from damping chamber.

Formula (10) is combined with (11):

$$
\Delta t=\frac{C_{\mathrm{d}} \varepsilon\left(2 R_{\mathrm{v} 3}-\varepsilon\right) \sqrt{2\left(P_{7}-P_{0}\right) / \rho}}{L_{\mathrm{v} 7}\left(R_{\mathrm{v} 3}^{2}-R_{\mathrm{v} 2}^{2}\right)} .
$$

Equations (12), (7), and (8) are used to solve $\Delta t$. The gap between the velocity control structure and cylinder body is modified to make $\Delta t$ equal to $\Delta t_{2}$, and the optimal clearance amount $\varepsilon$ is $0.036 \mathrm{~mm}$.

5.4. Validation. The speed control structure clearance of the reversing valve is modified and processed to $0.036 \mathrm{~mm}$, and the curve data are obtained as shown in Figure 11.

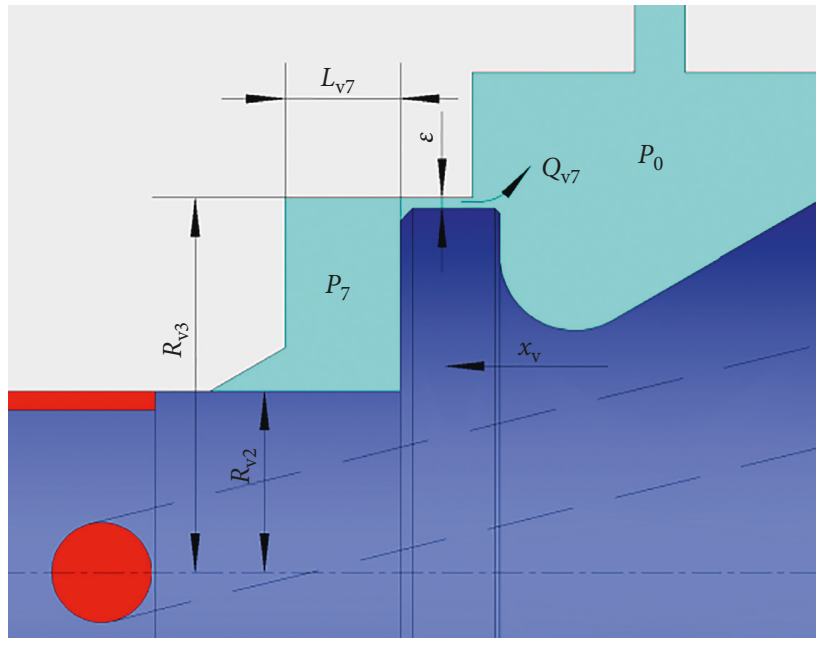

FIgURE 10: Speed control structure of the reversing valve.

After the structure modification, the pressure switching time of the left-right valve chamber pressure is obviously reduced, the pressure duration of the left valve chamber is $2.6 \mathrm{~ms}$, the pressure of the right valve chamber is $2.3 \mathrm{~ms}$, the impact frequency increases to $48 \mathrm{~Hz}$, the impact piston is directly rebound after the piston collision, the front-rear chamber pressure switches in time and there are no second collisions, and the high speed of the impact piston stroke is the fastest, which is increased to $12.1 \mathrm{~m} / \mathrm{s}$.

\section{Conclusions}

(1) The mechanism testing method of the hydraulic rock drill is designed, including calculation method and location of sensor installation. Test the data of the rock drill, analyze the test data, and complete the fault diagnosis of the rock drill according to the characteristics of the test data.

(2) The mathematical model of the impact and reversing mechanism of the hydraulic rock drill is established. The coupling condition of the impact piston and the reversing valve of the hydraulic rock drill is put forward. According to the optimum coupling condition, the optimum time for the movement of the reversing valve is obtained, and the best clearance 


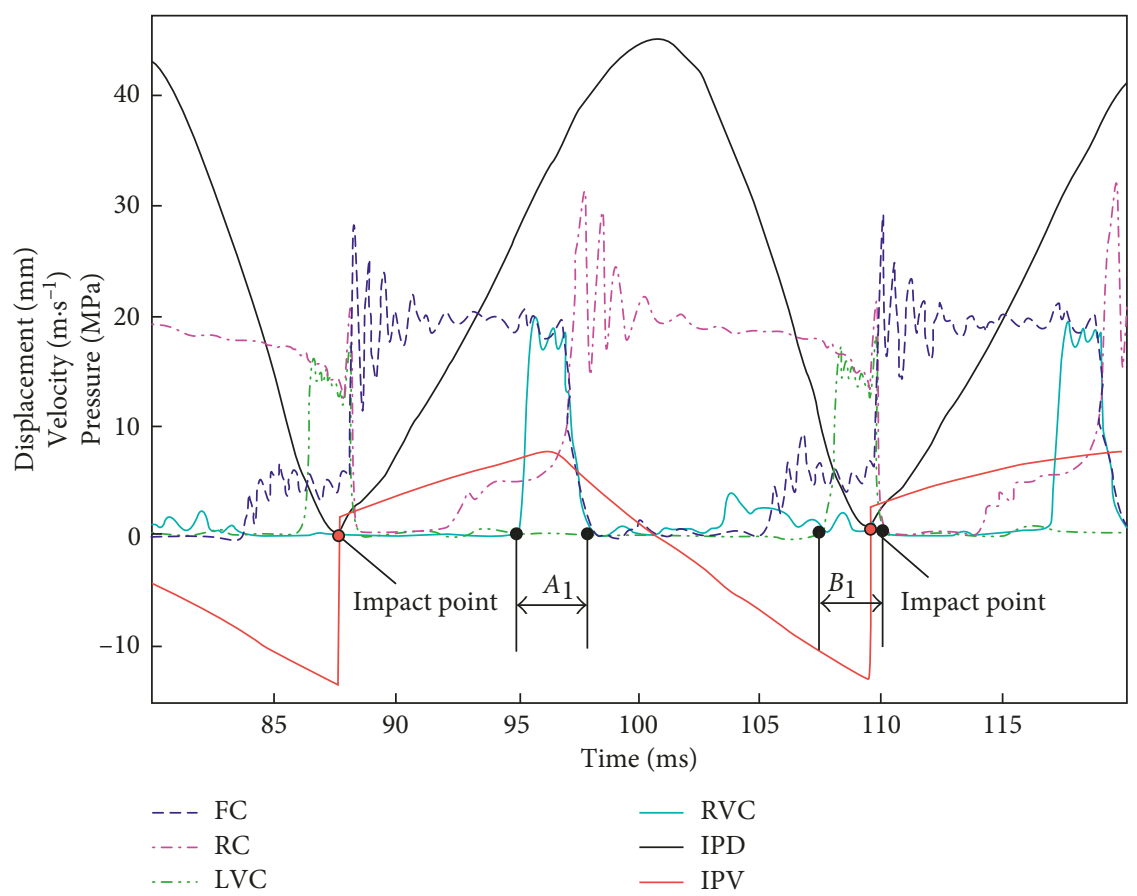

FIGURE 11: Testing and integral curves after structure modification. FC: front chamber; RC: rear chamber; LVC: left valve chamber; RVC: right valve chamber; IPD: impact piston displacement; IPV: impact piston velocity.

between the speed control structure of the reversing valve and the cylinder body is designed.

(3) The experiment is carried out based on the optimal clearance of the new reversing valve. Through the experimental data, it can be seen that the impact frequency of the rock drill is increased from $36 \mathrm{~Hz}$ to $48 \mathrm{~Hz}$, the velocity of the impact piston is increased from $9.7 \mathrm{~m} / \mathrm{s}$ to $12.1 \mathrm{~m} / \mathrm{s}$, and the overall performance of the rock drill is greatly improved. The internal mechanism testing method reacts more intuitively to the change law of the internal mechanism of the rock drill and provides a more direct and effective method for the design and production of a new rock drill, the study of the correctness of the design theory, and the actual use effect.

\section{Data Availability}

The data used to support the findings of this study are available from the corresponding author upon request.

\section{Conflicts of Interest}

The authors declare that they have no conflicts of interest.

\section{Acknowledgments}

This research is sponsored by Education Department General Item of Hunan Province (Grant no. 16C1090), Dr. Research Foundation from Hunan University of Arts and Science (Grant no. 16BSQD20), "R\&D and Industrialization of Rock Drilling Machines” (Grant no. XJT [2014] 239), Industrialization Development Project of Technological
Achievements of Universities in Hunan Province (15CY008), the Construct Program of the Key Discipline in Hunan Province (Mechanical Design and Theory) (XJF2011[76]), and Cooperative Demonstration Base of Universities in Hunan.

\section{References}

[1] Q. Hu, C. Yang, H. Zheng, and M. Chen, "Dynamic simulation and test research of impact performance of hydraulic rock drill with no constant-pressurized chamber," Automation in Construction, vol. 37, no. 1, pp. 211-216, 2014.

[2] M. Arffman, M. Marjamaki, and J. Keskinen, "Simulation of low pressure impactor collection efficiency curves," Journal of Aerosol Science, vol. 42, no. 5, pp. 329-340, 2011.

[3] S. Liu, H. Li, and H. Chang, "Drilling performance of rock drill by high-pressure water jet under different configuration modes," Shock and Vibration, vol. 2017, Article ID 5413823, 14 pages, 2017.

[4] P. Li, H. Zhang, S. Jiang, and W. Zhang, "Analysis and testing of load characteristics for rotary-percussive drilling of lunar rock simulant with a lunar regolith coring bit," Shock and Vibration, vol. 2017, Article ID 3012749, 15 pages, 2017.

[5] M. F. Shu, Q. H. He, H. Q. Zhao et al., "Study on simulation of impact performance and working pressure of hydraulic drifter," Journal of Wuhan University of Technology, vol. 33, no. 8, pp. 133-137, 2011.

[6] J. P. Hu and Q. Hu, "Oil pressure pulse features of a hydraulic impactor with an overlapped oil distributing valve," Journal of Vibration and Shock, vol. 33, no. 24, pp. 158-163, 2014.

[7] G. P. Yang, R. L. Wang, B. Chen et al., "Modeling and simulation of hydraulic breaker system," China Journal of Highway and Transport, vol. 24, no. 3, pp. 121-126, 2011.

[8] J. Y. Oh, G. H. Lee, H. S. Kang, and C. S. Song, "Modeling and performance analysis of rock drill drifters for rock stiffness," 
International Journal Precision Engineering and Manufacturing, vol. 13, no. 12, pp. 2187-2193, 2012.

[9] S. Kahraman, N. Bilgin, and C. Feridunoglu, "Dominant rock properties affecting the penetration rate of percussive drills," International Journal of Rock Mechanics and Mining Science, vol. 40, no. 5, pp. 711-723, 2003.

[10] L. E. Chiang and D. A. Elias, "Modeling impact in down-thehole rock drilling," International Journal of Rock Mechanics Mining Sciences, vol. 37, no. 4, pp. 599-613, 2000.

[11] G. Sun and M. Kleeberger, "Dynamic responses of hydraulic mobile crane with consideration of the drive system," Mechanism and Machine Theory, vol. 38, no. 12, pp. 1489$1508,2003$.

[12] Z. Liu, Y. F. Liao, X. X. Huang et al., "Research on step less adjustment theory and device of hydraulic impact machine," China Journal of Highway and Transport, vol. 119, no. 2, pp. 121-126, 2006.

[13] B. Lundberg and M. Okrouhlik, "Influence of 3D effects on the efficiency of percussive rock drilling," International Journal of Impact Engineering, vol. 25, no. 4, pp. 345-360, 2011.

[14] G. Sun and J. Liu, "Dynamic responses of hydraulic crane during luffing movement," Mechanism and Machine Theory, vol. 41, no. 11, pp. 1273-1288, 2006.

[15] Y. L. Li, F. Ma, and X. G. Geng, "Dynamic characteristics on double damping system of heavy hydraulic rock drill," Journal of China Coal Society, vol. 40, no. 7, pp. 1684-1691, 2015.

[16] Y. L. Li, F. Ma, and X. G. Geng, "Optimal design of performance parameters for the double damping system of a hydraulic rock drill," Chinese Journal of Engineering, vol. 37, no. 9, pp. 1183-1190, 2015.

[17] Y. L. Li, F. Ma, and X. G. Geng, "Effect of annular clearance inside the double damping chamber on the dynamic characteristics of a rock drill damping system," Journal of University of Science and Technology Beijing, vol. 36, no. 12, pp. 1676-1682, 2014. 


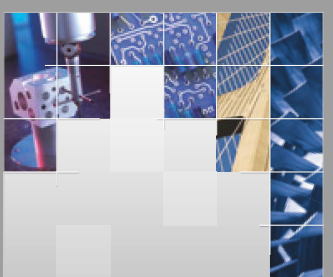

\section{Enfincering}
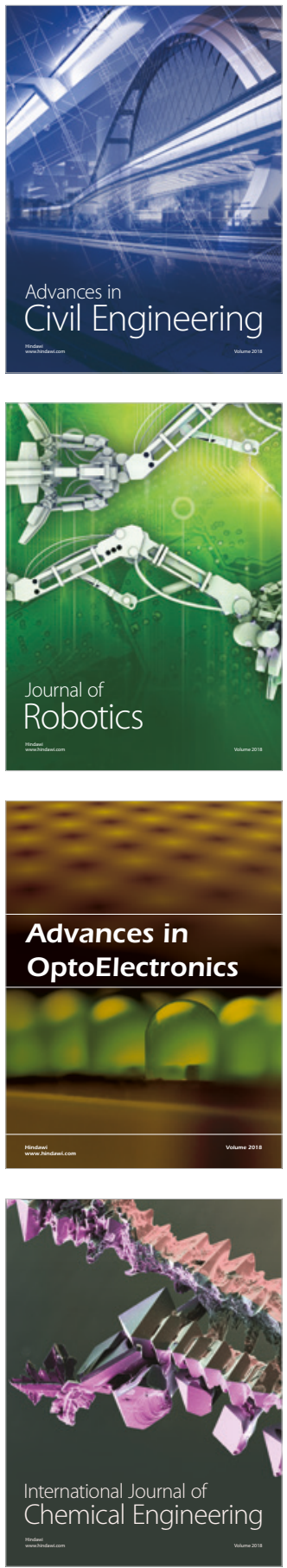

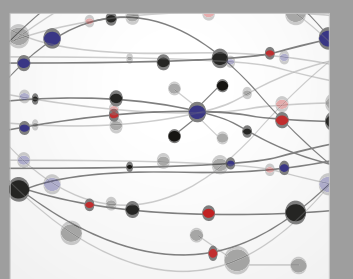

\section{Rotating \\ Machinery}

The Scientific World Journal

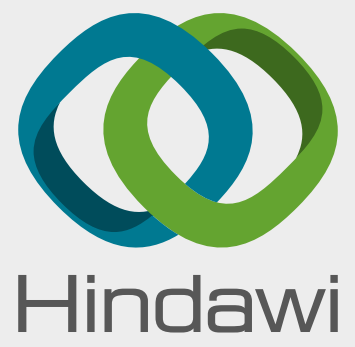

Submit your manuscripts at

www.hindawi.com
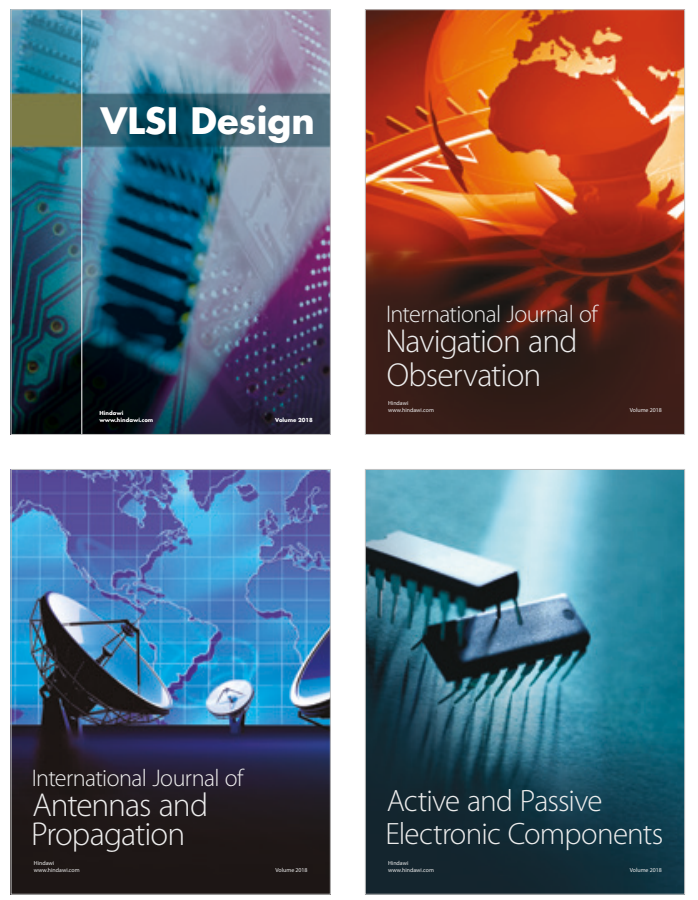
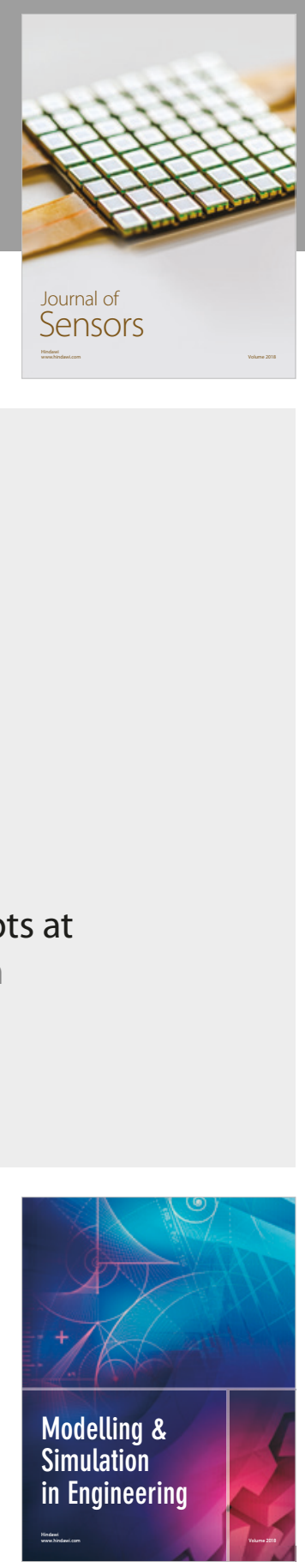

\section{Advances \\ Multimedia}
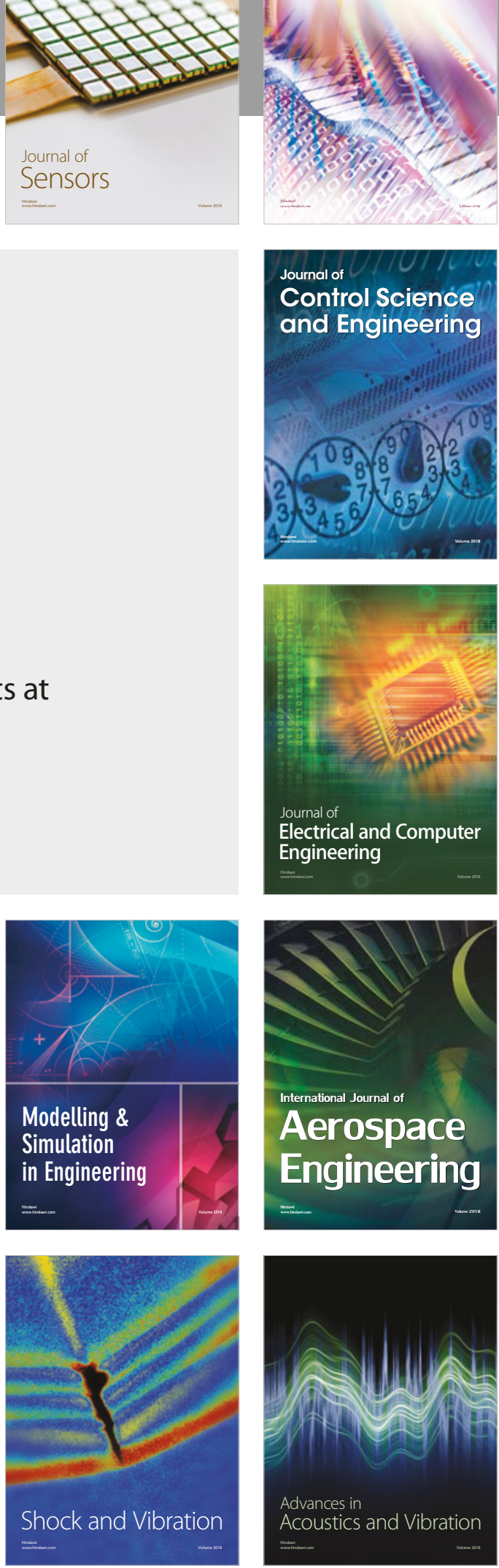